\title{
De què parlem els sociòlegs? \\ Quinze anys de publicacions a la revista PAPERS DE SOCIOlOGia (1987-2001)
}

\section{Antoni Morell Blanch}

Universitat de Lleida. Departament d'Economia Aplicada

Carrer de Jaume II, 73. Campus de Cappont. 25001 Lleida

antonio.morell@econap.udl.es

\section{Resum}

En aquest treball es realitza una anàlisi bibliomètrica i historiogràfica dels articles publicats a la revista PAPERS DE SOCIOLOGIA entre els anys 1987 i 2001, per tal de buscar-hi dades que ens permetin endinsar-nos en la realitat de la investigació sociològica que es duu a terme al nostre país, posant un èmfasi especial en les xarxes de col-laboració que s'estableixen entre els autors que publiquen les seves investigacions en aquesta revista.

Paraules clau: investigació sociològica, anàlisi bibliomètrica, xarxes de col-laboració.

Resumen. ¿De qué hablamos los sociólogos? Quince años de publicaciones de la revista PAPERS DE SOCIOLOGIA (1987-2001)

En este trabajo se realiza un análisis bibliométrico e historiográfico de los artículos publicados en la revista PAPERS DE SOCIOLOGIA entre los años 1987 y 2001, con el fin de buscar datos que nos permitan adentrarnos en la realidad de la investigación sociológica que se realiza en nuestro país, poniendo especial énfasis en las redes de colaboración que se establecen entre los autores que publican sus investigaciones en esta revista.

Palabras clave: investigación sociológica, análisis bibliométrico, redes de colaboración.

Abstract. What are sociologists dealing with?

In this work we make a bibliometrical analysis about the papers published in the PAPERS DE SocIOLOGIA journal between the years 1987 and 2001, in order to search data that allow us to get inside the reality of the sociological research being done in our country, with special emphasis in the collaborative networks that get established between the authors that publish their research in this journal.

Key words: sociological research, bibliometric analysis, collaborative networks.

\section{Sumari}

1. Introducció Annex 1. Institucions d'origen

2. L'activitat investigadora

3. Conclusions Bibliografia dels col-laboradors de la revista PAPERS 


\section{Introducció}

L'objecte d'aquest treball és proporcionar un coneixement més ampli dels àmbits temàtics que ocupen el treball dels sociòlegs. Amb aquesta finalitat, s'ha dut a terme una anàlisi bibliomètrica i historiogràfica dels articles publicats a la revista PAPERS DE SOCIOLOGIA, que des de la seva fundació, l'any 1972, és un punt de referència obligat per a tots els sociòlegs que desenvolupem la nostra tasca a Catalunya ${ }^{1}$. La metodologia bibliomètrica s'ocupa de la quantificació de la informació bibliogràfica susceptible de ser analitzada amb aplicacions a l'àrea de la documentació i de la ciència (Garfield, 1978). En aquest últim supòsit, els procediments bibliomètrics s'enquadrarien en l'enfocament externalista de la ciència o estudis socials de la ciència (Medina, 1982, 1983). Així, les dades reflectides en aquest treball ens permeten endinsar-nos en la realitat de la investigació sociològica que es duu a terme avui dia al nostre país, com també en la seva evolució entre els anys 1987 i 2001 . A més de la delimitació temàtica de la producció científica, ens interessa esbrinar les relacions de col-laboració entre investigadors, tant en l'àmbit nacional com internacional, ja que determinats autors (Gordon, 1980; Lawani, 1986) assenyalen que el resultat d'una col-laboració més gran entre els investigadors comporta més qualitat i impacte dels treballs. Cal indicar, en aquest sentit, que moltes vegades la coautoria és el resultat de l'activitat que els investigadors duen a terme en el marc d'instituts, grups de recerca consolidats, equips de treball sobre determinades temàtiques, etc.

D'altra banda, cal recordar que, com indica Tezanos (1995), la definició de la sociologia a partir del que realment fan els sociòlegs no tan sols permet portar el debat sobre l'objecte d'estudi de la sociologia a l'àmbit de les dades empíriques, sinó que també permet enfrontar-nos directament amb la sociologia en el seu desenvolupament més quotidià. En aquest sentit, la bibliometria, segons López i Escalada (1999: 162-163), «s'ocupa de quantificar una dimensió concreta de la ciència: aquella que queda reflectida en documents divulgats a través dels diversos canals de comunicació científica. Els sociòlegs de la ciència reconeixen que la comunicació científica és un element essencial sense el qual la ciència no podria progressar i es detindria el progrés cientificotècnic de la societat». Alguns autors donen tanta importància a aquest aspecte que defineixen formalment la ciència com allò que es publica en els articles científics (Price, 1980).

Aquesta afirmació és la que dóna validesa al nostre estudi, en tant que és possible conèixer les característiques del treball que desenvolupa la comunitat científica a partir de les aportacions que es publiquen en forma d'articles. Per tant, quan estudiem una revista de referència per a una disciplina, com és el cas de la revista PAPERS, tenim accés a tot un seguit d'indicadors que ens pro-

1. La disponibilitat de revistes és, segons Shils (1971), un dels tres principals indicadors de la institucionalització d'una disciplina, juntament amb la disponibilitat d'instituts d'investigació i la disponibilitat d'estudiants. 
porcionen informació de l'activitat investigadora que es duu a terme en el marc d'aquesta disciplina (López y Escalada, 1999; Suriñach i altres, 2002).

En aquest sentit, un dels primers reptes al qual hem hagut de fer front és la delimitació temàtica o classificació dels articles publicats. D'entrada, hem limitat la nostra anàlisi a les aportacions publicades en forma d'article; és a dir, no incloem ni tenim en compte en la nostra anàlisi les aportacions publicades sota el format de ressenyes, notes de lectura, reculls bibliogràfics, etc. El resultat ha estat la recopilació de 332 articles publicats en la revista durant el període comprès entre els anys anteriorment assenyalats, que és la font d'informació que nosaltres utilitzem per arribar a extreure les conclusions que tot seguit comentem.

\section{L'activitat investigadora}

La mitjana de publicació d'articles per any en el període considerat ha estat de 22,13 , la qual cosa ens situa a nivells similars a d'altres revistes espanyoles ${ }^{2}$. L'evolució temporal de la productivitat queda reflectida en el quadre 1 . Pot observar-se l'existència de certes fluctuacions que, com ja s'ha dit, situen la mitjana anual en xifres properes a la d'altres revistes d'àmbit nacional. Queda palès, però, que quan es realitza l'edició conjunta de més d'un número en un únic volum, aquest fet comporta una certa tendència a la baixa pel que fa al nombre d'articles publicats $i$ alhora explica que la mitjana d'articles publicats sigui inferior a la resta del període. Així succeeix, per posar-ne un exemple, en el número 63/64, corresponent a l'any 2001. Cal destacar, d'altra banda, que la quantitat de números publicats varia en funció dels anys ${ }^{3}$, la qual cosa també pot repercutir significativament en el nombre d'articles publicats. Finalment, cal esmentar que, l'any 1993, amb motiu dels vint anys de publicació de la revista, es dedica una bona part del número 42 a fer una revisió de les col.laboracions fins aleshores aparegudes. En tot cas, pot apreciar-se una certa tendència a l'alça pel que fa al nombre d'articles publicats anualment, que assoleix el seu nivell màxim els anys 1997 i 2000, amb 40 i 37 articles publicats, respectivament, si bé cal assenyalar la forta davallada de l'any 2001, pels motius que ja s'han comentat i que ens retornen als nivells d'inici del període considerat ${ }^{4}$.

2. A tall d'exemple, es pot dir que la mitjana d'articles per any publicats a la revista REIS durant el període 1978-1997 ha estat de 30,8 (López i Escalada, 1999; Durán, 2001).

3. Tres números els anys 2001, 2000, 1999, 1998, 1997, 1996, 1995, 1993 i 1990; dos números els anys 1994, 1992, 1991, 1989 i 1988, i un número l’any 1987.

4. Segons Hicks (1999), la investigació en ciències socials es caracteritza per la presència de més paradigmes en competència que no pas en les ciències naturals, fet que dóna lloc a publicacions poliglotes i fragmentades, i a una proporció més gran de llibres publicats i a una publicació menys nombrosa d'articles: la producció d'articles representa el $85 \%$ del total en el cas de les ciències naturals; mentre que en les ciències socials tan sols arriba al $61 \%$. A Espanya, la proporció d'articles dels investigadors de CSIC en l'àmbit de les humanitats i les ciències socials és del $54 \%$ de la producció total, xifra que s'incrementa fins al $81 \%$ en les àrees de ciències (Durán, 2001). 
Quadre 1. Evolució temporal de la productivitat: anys i articles publicats.

\begin{tabular}{llll}
\hline 2001 & 17 & 1993 & 18 \\
2000 & 37 & 1992 & 14 \\
1999 & 25 & 1991 & 12 \\
1998 & 30 & 1990 & 21 \\
1997 & 40 & 1989 & 14 \\
1996 & 28 & 1988 & 17 \\
1995 & 26 & 1987 & 11 \\
1994 & 22 & & \\
\hline
\end{tabular}

Resulta difícil determinar els motius de la fluctuació en el nombre d'articles publicats, més enllà del que ens indica el diferent nombre de volums que poden publicar-se anualment, i que moltes vegades depèn més de factors relacionats amb la gestió de la revista que no pas de la recepció i selecció d'articles per part del consell de redacció. Tanmateix, caldria plantejar-se si l'extensió condicionarà el nombre d'articles que la revista pot encabir a les seves pàgines. En aquest sentit, i més enllà de les normes que la revista dóna als seus col-laboradors pel que fa, per exemple, a l'extensió dels treballs que s'han de publicar, Suriñach i altres (2002: 114) apunten la idea que, "tenint en compte que els editors tenen un nombre limitat de pàgines per volum i de volums per any, sembla lògic pensar que intentaran assignar el major (o menor) nombre de pàgines possible als articles de major (o menor) qualitat durant el procés d'avaluació».

Cal també tenir en compte que, des dels consells de redacció de les revistes, s'impulsa la publicació de volums monogràfics dedicats a una determinada temàtica; alhora, la participació en aquests volums d'autors o estudis d'inequívoca rellevància per a la matèria pot condicionar el nombre final d'articles que es pot publicar. D'altra banda, cal indicar que no hem trobat l'existència d'una correlació clara entre la realització de congressos de sociologia i el nombre de treballs publicats anualment. En aquest sentit, podria apuntar-se la idea que la realització de congressos marca l'agenda dels investigadors i que, per tant, un cop realitzat el congrés i exposades les conclusions de les seves investigacions, seria el moment de divulgar-les per mitjà d'altres canals, com ara les publicacions periòdiques de sociologia; però, malgrat tot, les dades no corroboren aquesta hipòtesi. Així doncs, més enllà de les idees apuntades, resulta difícil establir de forma contundent arguments explicatius que permetin dir el perquè de la fluctuació en el nombre d'articles que anualment ha publicat la revista.

Tant o més important que l'evolució temporal de la productivitat és localitzar els responsables de la producció científica. El quadre 2 reflecteix que hi ha participat un total de $422 \mathrm{col}$-laboradors. Com s'observa, la gran majoria dels articles estan signats per un sol autor. Això succeeix en el 80,72\% dels 
Quadre 2. Distribució dels autors segons el nombre d'articles.

\begin{tabular}{lccc}
\hline Autors & Articles & $\%$ & \% acumulat \\
\hline 1 & 268 & 80,72 & 80,72 \\
2 & 45 & 13,55 & 94,28 \\
3 & 10 & 3,01 & 97,29 \\
4 & 6 & 1,81 & 99,10 \\
5 & 2 & 0,60 & 99,70 \\
No hi consta & 1 & 0,30 & 100,00 \\
\hline
\end{tabular}

$\operatorname{casos}^{5}$, percentatge que disminueix progressivament a mesura que augmenta el nombre d'autors. Aquest fet deixa palesa la poca col-laboració que existeix entre els sociòlegs a l'hora d'afrontar les seves investigacions i que el treball en equip és encara una opció molt minoritària en la nostra disciplina. Com indica Manuel Navarro (2001), la investigació universitària continua tenint una escassa institucionalització i continua caracteritzant-se per la seva individualitat, la seva discontinuïtat i la seva precarietat. Segons la seva opinió, l'arrel d'aquestes notes distintives de la investigació universitària en l'àmbit de la sociologia s'ha de buscar en la manca de finançament. Tanmateix, aquest fet contrasta amb el que succeeix en els congressos, on la col-laboració entre els sociòlegs a l'hora de presentar les seves comunicacions acostuma a ser molt més habitual.

Si prenem com a dada la filiació institucional dels autors, veiem que hi ha un total de 39 articles en què no figura aquesta informació, és a dir, l'11,71\%. A més d'aquests, hi apareix un total de 87 institucions, entre les quals 49 són de fora de l'Estat espanyol ${ }^{6}$. Algunes de les més productives hi apareixen en l'ordre següent:

- Universitat Autònoma de Barcelona

- Universitat de Barcelona

- Universitat de l'Havana

- Universitat Complutense de Madrid

- Universitat de Granada

D'altra banda, cal assenyalar que un 18,97\% dels articles estan signats si més no per un autor que desenvolupa la seva activitat professional en una ins-

5. A tall d'exemple, es pot recordar que el nombre d'articles signats per un sol autor a la Revista Española de Investigaciones Sociológicas durant el període 1978-1997 ascendeix a 530, la qual cosa significa el 86,04\% del total d'articles publicats (López i Escalada, 1999: 167); és a dir, l'índex de col-laboració en aquesta revista se situa en un 1,18, mentre que en el cas de la revista PAPERS, aquest és de l'1,27.

6. Vegeu l'annex 1. 
titució ubicada fora de l'Estat espanyol. Concretament, els percentatges de la col-laboració institucional dels autors respon a les xifres següents ${ }^{7}$ :

- Col-laboració entre autors d'una mateixa universitat espanyola: 9,94\%

- Col-laboració entre autors de diferents universitats espanyoles: 3,92\%

- Col.laboració entre autors d'universitats espanyoles i estrangeres: 1,51\%

- Col-laboració entre autors d'universitats estrangeres: 2,11\%

Cal tenir en compte que les col-laboracions entre autors d'una mateixa universitat es realitzen, majoritàriament, entre membres d'un mateix departament $^{8}$, o bé entre membres de determinats grups de treball o recerca. En tot cas, cal assenyalar que la coautoria en l'àmbit de les ciències socials és encara un fet limitat que presenta uns índexs molt allunyats respecte d'altres disciplines, com és el cas de les ciències experimentals (Sanz i altres, 1998). Així, per exemple, si a principis del segle XX, el 80\%, aproximadament, dels treballs publicats a Chemical Abstracts estava signat per un únic autor, avui aquesta tendència s'ha invertit. Com ja s'ha comentat, determinats autors (Gordon, 1980; Lawani, 1986) consideren que la col-laboració entre investigadors té un efecte positiu pel que fa a la producció científica. Altres hipòtesis relacionen el nivell de col-laboració amb les ajudes rebudes, en el sentit que els ajuts financers permeten la formació de grups d'investigació (López i Escalada, 1999). En l'àmbit de la sociologia, aquesta hipòtesi va ser desenvolupada per Hirsch i Singleton (1965) a partir dels articles publicats en col-laboració en revistes de sociologia entre 1934 i 1964.

Un altre indicador que resulta interessant és el nombre de pàgines publicades i/o el nombre de pàgines ponderades pel nombre d'autors. Si bé aquest és un indicador que, com expliquen Sanz i altres (1999), tan sols s'acostuma a utilitzar quan s'observen les collaboracions en revistes d'alt prestigi, pot proporcionar una informació prou interessant per tenir-la en compte. Així, i segons el nombre d'autors que signen els treballs, ens trobem amb les dades següents (quadre 3).

Com pot observar-se, en els treballs publicats fins a un màxim de tres autors, no s'hi aprecien diferències significatives respecte a l'extensió, que se situa al voltant de les 18,29 pàgines. Ara bé, quan el nombre de col.laboradors que participen en l'elaboració de l'article supera aquesta xifra, s'aprecia una certa tendència a incrementar paral-lelament l'extensió del treball publicat. Evidentment, si l'element que s'ha de tenir en compte és el nombre de pàgines

7. Les dades mostren que la tendència a la col-laboració al llarg del període s'ha anat consolidant i ha arribat a assolir xifres prou significatives en l'últim quinquenni del període considerat, fet que es valora positivament. Concretament, el percentatge del nombre de treballs que són fruit de la col-laboració entre dos autors o més se situa en els anys 1997, 1998, 1999,2000 i 200, en el 20,00\%, el 40,00\%, el 28,00\%, el 24,32\% i el 23,53\%, respectivament.

8. Els articles que són fruit de la col-laboració entre membres d'un mateix departament representen el 8,73\% del total d'articles publicats durant el període 1987-2001; per contra, els treballs que són resultat de la col-laboració entre membres de diferents departaments (d'una mateixa universitat) tan sols assoleixen l'1,20\% del total. 
Quadre 3. Distribució dels autors segons el nombre de pàgines publicades.

\begin{tabular}{lcc}
\hline Nombre d'autors & Nombre de pàgines & Nombre de pàgines ponderades \\
\hline 1 & 18,77 & 18,77 \\
2 & 17,29 & 8,65 \\
3 & 18,8 & 6,27 \\
4 & 23 & 2,75 \\
5 & 38,5 & 7,7 \\
No hi consta & 34 & - \\
\hline
\end{tabular}

ponderades en funció dels autors, queda clar que, en termes generals, l'extensió disminueix a mesura que s'incrementa el nombre d'autors. Tanmateix, cal assenyalar que aquest és un indicador d'una importància relativa, ja que és clar que la tendència no ha de ser la d'incrementar el nombre de pàgines a mesura que augmenta el nombre d'autors: es tracta de transmetre els resultats d'una investigació de la forma més rigorosa, didàctica i sintètica possible, la qual cosa no té res a veure amb el nombre de persones que hi participen.

Més interessant que les qüestions comentades fins ara és esbrinar les relacions institucionals que s'estableixen entre els autors a l'hora de dur a terme les seves investigacions i divulgar els seus resultats, i també observar la temàtica que constitueix el seu objecte d'estudi. Evidentment, les branques d'activitat científica en l'àmbit d'actuació dels sociòlegs varia segons els seus interessos, el marc institucional en el qual desenvolupen la seva activitat, i la pròpia dinàmica i evolució de la disciplina, que permanentment obre nous àmbits d'anàlisi de la realitat social en la mesura que varien les demandes de la societat.

En aquest sentit, no ha estat facil agrupar la varietat de temàtiques tractades en els articles publicats en una llista limitada de matèries que resultés suficientment operativa i alhora il.lustrativa de l'activitat que duen a terme els sociòlegs. Per motius operatius, s'han agrupat les àrees temàtiques que han estat objecte de publicacions fins a reduir-les a les següents:

\section{[01] Metodologia i epistemologia}

[02] Teoria sociològica

[03] Sociologia de la població; demografia

[04] Sociologia de la família

[05] Sociologia rural

[06] Sociologia econòmica: sociologia del treball i de l'empresa; relacions laborals i sindicalisme; formació i recursos humans

[07] Sociologia política; relacions internacionals

[08] Sociologia de l'oci i l'esport

[09] Sociologia del gènere

[10] Estructura social, desigualtat i classes socials; estat de benestar i polítiques socials; problemes socials 
[11] Identitats col-lectives; moviments socials i acció col-lectiva; participació social

[12] Sociologia de l'educació

[13] Sociologia de la religió

[14] Sociologia de les edats: infancia, joventut i vellesa

[15] Sociologia de les migracions, minories ètniques i multiculturalitat

[16] Sociologia de la moda i el consum

[17] Ecologia i medi ambient

[18] Sociologia de les organitzacions

[19] Sociologia de la cultura i l'art

[20] Sociologia de la salut

Aquesta classificació respon, en bona mesura, a les àrees de treball utilitzades en els últims congressos de la Federació Espanyola de Sociologia (FES) i/o de l'Associació Catalana de Sociologia (ACS), si bé s'ha adaptat perquè respongui millor als propòsits d'aquest article. Sens dubte, no ha estat facil ubicar determinats articles dins d'un àmbit temàtic o un altre. Per exemple, s'han trobat articles que tracten el fenomen de la migració o el treball des de la perspectiva del gènere; en altres casos, articles que s'inclouen dins l'àmbit de la sociologia de l'educació fixen la seva atenció en qüestions vinculades, per exemple, a la inserció de determinades minories ètniques en el procés educatiu. El criteri seguit ha estat determinar quina era la principal hipòtesi reflectida en l'article i els arguments que l'autor utilitza per donar-hi suport. També s'ha tingut en compte si els articles s'inclö̈en en un número monogràfic dedicat a una determinada temàtica. Tanmateix, resulta de gran utilitat guiar-se per les paraules clau. De fet, aquestes proporcionen una informació de gran utilitat per determinar la temàtica tractada en l'article més enllà de l'àmbit temàtic en el qual finalment queda ubicat.

Amb tot, es creu erroni el criteri de fer encabir tots els articles en una única àrea temàtica i/o especialitat sociològica; per aquest motiu i seguint el criteri utilitzat en treballs anteriors (Marín i altres, 1993; Sanz i altres, 1999; López i altres, 1999; etc.), de vegades, s'han assignat dos codis diferents a un mateix article per tal de reflectir més acuradament quins són els àmbits d'estudi que ocupen el treball dels sociòlegs. En total s'han obtingut quatre-centes entrades, distribuïdes de la manera següent (quadre 4).

Pot observar-se que les àrees temàtiques que tenen una importància percentual més gran amb relació al total d'articles publicats (superior al 5\%) són les següents: [07] Sociologia política; relacions internacionals; [15] Sociologia de les migracions, minories ètniques i multiculturalitat; [02] Teoria sociològica; [06] Sociologia econòmica: sociologia del treball i de l'empresa; relacions laborals i sindicalisme; formació i recursos humans; [01] Metodologia i epistemologia, i [10] Estructura social, desigualtat i classes socials; estat de benestar i polítiques socials; problemes socials.

L'evolució temporal, però, no mostra sempre la mateixa tendència, de manera que, en termes generals, tot i produir-se fluctuacions segons els anys, es pot 
Quadre 4. Distribució dels articles per àmbit temàtic.

\begin{tabular}{|c|c|c|c|c|c|c|c|c|c|c|c|c|c|c|c|c|c|}
\hline Codi ${ }^{1}$ & & 88 & 89 & 90 & 91 & 92 & 93 & 94 & 95 & 96 & 97 & 98 & 99 & 00 & 01 & Total & $\%$ \\
\hline [01] & 0 & 2 & 2 & 1 & 6 & 1 & 1 & 0 & 2 & 8 & 0 & 6 & 1 & 2 & 4 & 36 & 9,00 \\
\hline 2] & 1 & 1 & 4 & 0 & 1 & 0 & 2 & 0 & 1 & 8 & 1 & 8 & 5 & 9 & 2 & 43 & 10,75 \\
\hline 03] & 0 & 0 & 0 & 0 & 0 & 0 & 0 & 0 & 0 & 0 & 3 & 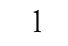 & . & 0 & 0 & 4 & 1,00 \\
\hline 04] & 0 & 1 & 0 & 0 & 5 & 0 & 1 & 1 & 2 & 0 & 4 & 2 & 1 & 0 & 0 & 17 & 4,25 \\
\hline 5] & 0 & 0 & 0 & 0 & 0 & 0 & 0 & 0 & 3 & 0 & 1 & 1 & 0 & 1 & 0 & 6 & 1,50 \\
\hline 06] & 3 & 1 & 5 & 2 & 1 & 3 & 0 & 2 & 1 & 1 & 3 & 3 & 10 & 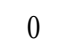 & 4 & 39 & 9,75 \\
\hline 07] & 3 & 0 & 3 & 12 & 0 & 3 & 6 & 4 & 10 & 8 & 4 & 2 & 4 & 2 & 1 & 62 & 15,50 \\
\hline 08] & 0 & 0 & 0 & 0 & 0 & 5 & 1 & 0 & 0 & 0 & 1 & 0 & 0 & 0 & 0 & 7 & 1,75 \\
\hline 9] & 0 & 7 & 0 & 0 & 0 & 0 & 0 & 1 & 2 & 0 & 3 & 1 & 2 & 9 & 4 & 29 & 7,25 \\
\hline 10$]$ & 4 & 1 & 0 & 3 & 0 & 1 & 0 & 2 & 0 & 3 & 3 & 0 & 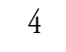 & 4 & 2 & 27 & 6,75 \\
\hline 11] & 0 & 0 & 0 & 0 & 0 & 0 & 0 & 5 & 1 & 0 & 3 & 4 & 2 & 2 & 1 & 18 & 4,50 \\
\hline 12] & 0 & 3 & 0 & 0 & 0 & 1 & 0 & 0 & 1 & 0 & 6 & 2 & 0 & 0 & 1 & 14 & 3,50 \\
\hline 13] & 0 & 0 & 0 & 0 & 0 & 0 & 0 & 0 & 1 & 0 & 1 & 1 & . & 0 & 0 & 3 & 0,75 \\
\hline 14] & 0 & 0 & 0 & 0 & 0 & 1 & 8 & 0 & 0 & 0 & 2 & 1 & 1 & 2 & 2 & 17 & 4,25 \\
\hline 15$]$ & 0 & 0 & 0 & 0 & 1 & 0 & 0 & 14 & 1 & 0 & 3 & 1 & 1 & 21 & 1 & 43 & 10,75 \\
\hline 16] & 0 & 0 & 0 & 0 & 0 & 0 & 0 & 0 & 2 & 1 & 2 & 1 & 0 & 0 & 0 & 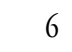 & 1,50 \\
\hline 17] & 0 & 0 & 0 & 1 & 0 & 1 & 0 & 0 & 1 & 0 & 1 & 0 & 1 & 0 & 0 & 5 & 1,25 \\
\hline [18] & 0 & 0 & 0 & 0 & 0 & 1 & 0 & 1 & 2 & 0 & 1 & 0 & 0 & 0 & 1 & 6 & 1,50 \\
\hline [19] & 0 & 6 & 0 & 1 & 0 & 1 & 0 & 1 & 1 & 1 & 1 & 0 & 0 & 0 & 0 & 12 & 3,00 \\
\hline [20] & 0 & 0 & 0 & 1 & 0 & 0 & 1 & 0 & 0 & 0 & 3 & 0 & 1 & 0 & 0 & 6 & 1,50 \\
\hline Total & 11 & 22 & 14 & 21 & 14 & 18 & 20 & 31 & 31 & 30 & 46 & 34 & 33 & 52 & 23 & 400 & 00 \\
\hline$\%$ & 2,8 & 5,5 & 3,5 & 5,3 & 3,5 & 4,5 & 5,0 & 7,8 & $8 \quad 7,8$ & 7,5 & 11,5 & 8,5 & 8,3 & 13,0 & & 8100 & \\
\hline
\end{tabular}

1. Vegeu la llista de les àrees temàtiques.

dir que la distribució de les col-laboracions en el transcurs del període ha estat força equilibrada en els apartats [01] Metodologia i epistemologia; [10] Estructura social, desigualtat i classes socials; estat de benestar i polítiques socials; problemes socials, i [06] Sociologia econòmica: sociologia del treball i de l'empresa; relacions laborals i sindicalisme; formació i recursos humans (tot i que en aquest darrer destaca l'elevat nombre d'articles publicats l'any 1999). Els articles vinculats a la temàtica [07] Sociologia política; relacions internacionals, mostren una certa tendència a la baixa, que s'inicia l'any 1995. Finalment, la importància relativa dels articles relacionats amb les temàtiques [02] Teoria sociològica i [15] Sociologia de les migracions, minories ètniques i multiculturalitat, s'incrementa i pren força a partir del segon quinquenni de la dècada dels anys noranta. La mateixa tendència s'observa en altres àrees temàtiques, com ara, per exemple, [09] Sociologia del gènere i [11] Identitats col-lectives; moviments socials i acció col-lectiva; participació social. 
D’altra banda, és interessant reflectir les àrees temàtiques en funció de les colllaboracions detectades en la publicació dels articles. Cal pensar en la possibilitat que el mateix procés d'especialització del treball científic porti a una discriminació dels àmbits temàtics dependents de les institucions de procedència de les investigacions, fet que seria un indicatiu de l'existència de línies de recerca definides $\mathrm{o}$, fins i tot, de col-laboracions institucionals en l'àmbit de determinades àrees temàtiques. Per aquest motiu, és interessant esbrinar quins àmbits de la disciplina sociològica mostren més tendència a establir xarxes de col-laboració (quadre 5).

Si s'interrelaciona la informació que proporcionen els quadres 4 i 5 , es veu que l'índex mitjà de col-laboració en funció dels articles publicats distribuïts

Quadre 5. Distribució de les colllaboracions per àmbit temàtic.

\begin{tabular}{|c|c|c|c|c|c|c|}
\hline Codi & A & B & $\mathrm{C}$ & $\mathrm{D}$ & Total & $\%$ \\
\hline$[01]$ & 5 & 4 & 1 & & 10 & 14,08 \\
\hline$[02]$ & 2 & 3 & & 1 & 6 & 8,45 \\
\hline$[03]$ & & & & 1 & 1 & 1,41 \\
\hline [04] & 2 & 1 & & & 3 & 4,23 \\
\hline [05] & & & & & 0 & 0,00 \\
\hline$[06]$ & 8 & 2 & 1 & 1 & 12 & 16,90 \\
\hline [07] & 7 & 1 & & 1 & 9 & 12,68 \\
\hline$[08]$ & & & 1 & & 1 & 1,41 \\
\hline [09] & 2 & & & 3 & 5 & 7,04 \\
\hline [10] & 2 & & 1 & 1 & 4 & 5,63 \\
\hline [11] & 2 & & & & 2 & 2,82 \\
\hline [12] & 3 & & 1 & & 4 & 5,63 \\
\hline [13] & & & & & 0 & 0,00 \\
\hline [14] & 1 & & & & 1 & 1,41 \\
\hline [15] & 2 & 3 & 2 & 3 & 10 & 14,08 \\
\hline [16] & & & & & 0 & 0,00 \\
\hline [17] & & & & & 0 & 0,00 \\
\hline$[18]$ & 1 & & & & 1 & 1,41 \\
\hline [19] & 1 & & & & 1 & 1,41 \\
\hline [20] & 1 & & & & 1 & 1,41 \\
\hline Total & 39 & 14 & 7 & 11 & 71 & 100 \\
\hline$\%$ & 54,93 & 19,72 & 9,86 & 15,49 & 100 & \\
\hline
\end{tabular}

\section{Codis:}

A: Col-laboració entre autors d'una mateixa universitat ubicada dins del territori espanyol.

B: Col-laboració entre autors de diferents universitats ubicades dins del territori espanyol.

C: Col-laboració entre autors d'universitats ubicades dins i fora del territori espanyol.

D: Col-laboració entre autors d'universitats ubicades fora del territori espanyol. 
per àrees temàtiques se situa en el $17,75 \%$. Hi ha cinc àrees que superen aquest percentatge: [06] Sociologia econòmica: sociologia del treball i de l'empresa; relacions laborals i sindicalisme; formació i recursos humans, on el 30,77\% dels articles publicats són fruit de la col-laboració entre diversos autors; [12] Sociologia de l'educació, amb el 28,57\%; [01] Metodologia i epistemologia, amb el 27,78\%; [03] Sociologia de la població; demografia, amb el 25,00\%, i finalment [15] Sociologia de les migracions, minories ètniques i multiculturalitat, amb un percentatge d'articles publicats en forma de col-laboració que se situa en el $23,26 \%$ del total.

No volem acabar aquest apartat sense parlar de les llengües en què es publiquen els articles. Certament, el fet que la revista PAPERS sigui una publicació del Departament de Sociologia de la Universitat Autònoma de Barcelona hauria d'implicar que el català fos la seva llengua de referència. No obstant això, quedaria oberta a col-laboracions en altres llengües, especialment la castellana i l'anglesa. D'aquesta manera, s'amplia el seu àmbit de difusió i al mateix temps es dóna la possibilitat que hi publiqui un nombre més elevat d'investigadors, la qual cosa, sense cap mena de dubte, contribueix a augmentar la qualitat de la publicació i a enriquir les seves contribucions. Així, en el quadre 6 es presenta la relació dels treballs publicats en funció de la llengua emprada pels seus autors, i, paral.lelament, en el quadre 7 , es presenta la llengua emprada en els articles que provenen d'universitats catalanes ${ }^{9}$. Les dades són prou concloents:

Quadre 6. Distribució dels articles en funció de la llengua.

\begin{tabular}{lc}
\hline Llengua & $\%$ \\
\hline Castellana & 82,53 \\
Catalana & 14,76 \\
Anglesa & 2,41 \\
Italiana & 0,30 \\
\hline Total & 100 \\
\hline
\end{tabular}

Quadre 7. Distribució dels articles en funció de la llengua. Universitats amb seu a Catalunya.

\begin{tabular}{lc}
\hline Llengua & $\%$ \\
\hline Castellana & 76,47 \\
Catalana & 22,06 \\
Anglesa & 1,47 \\
\hline Total & 100 \\
\hline
\end{tabular}

9. En el cas d'articles signats per més d'un autor, s'inclouen en aquesta categoria tots aquells en què almenys n'hi ha un que desenvolupa la seva activitat en una universitat amb seu a Catalunya. 
el català és la llengua minoritària, fins i tot quan les col-laboracions procedeixen d'autors que desenvolupen la seva tasca professional a les universitats catalanes.

El fet pot respondre a la voluntat dels autors per donar més difusió als seus treballs d'investigació, cosa que portaria a emprar la llengua castellana en lloc de la pròpia. Tanmateix, podria argumentar-se que aquesta manera de procedir hauria de portar també a augmentar la presència de la llengua anglesa, atès l'àmbit de l'activitat professional en el qual ens movem els docents universitaris. Malgrat tot, cal no oblidar que la difusió de la revista PAPERS es duu a terme majoritàriament entre els universitaris de l'Estat espanyol i altres universitats de parla castellana, cosa que explicaria la presència majoritària d'aquesta llengua. Caldrà veure com aquesta qüestió evoluciona en el futur, ja que, certament, a excepció d'alguna col-laboració esporàdica, la gran majoria d'articles en llengua anglesa s'esdevé a partir de l'any 2000. Amb tot, aquesta dada no sembla prou concloent per preveure què succeirà en els pròxims anys i si hi haurà variacions significatives pel que fa a la llengua emprada preferentment pels col-laboradors de la revista.

\section{Conclusions}

Una primera valoració que podem extreure de les dades exposades anteriorment és que l'àmbit temàtic de la sociologia és molt ampli i dinàmic, i necessàriament qualsevol classificació pot portar a resultats esbiaixats. En tot cas, i malgrat aquesta constatació, pot observar-se una certa evolució temporal pel que fa a la distribució temàtica, en el sentit que determinades qüestions o camps temàtics centren cada vegada més l'atenció dels sociòlegs, alhora que d'altres deixen de constituir un camp prioritari d'investigació. De tota manera, encara que la línia editorial de les revistes de sociologia que avui es publiquen a Espanya pugui determinar el contingut dels articles que són acceptats per a la seva publicació, a gran trets no es detecten diferències significatives.

Així, segons indica Durán (2001), els temes amb més publicacions a la Revista Española de Investigaciones Sociológicas (REIS) ${ }^{10}$ són: 1) Actituds. Opinió pública. Mitjans de comunicació; 2) Estructura social. Canvi social. Moviments socials; 3) Partits polítics. Cultura política. Eleccions; 4) Antropologia. Història. Religió; 5) Teoria sociològica; 6) Demografia. Població; 7) Psicologia social. Grups. Organitzacions. D’altra banda, la distribució dels articles publicats a la revista Sistema durant el període 1971-1991 ha estat la següent: Ciència política (18,99\%). Marxisme i socialisme (16,96\%). Dret (12,75\%). Sociologia (9,36\%). Història (8,27\%). Filosofia (7,19\%). Pensament espanyol $(6,91 \%)$. Economia i treball (4,61\%). Nacionalisme, regionalisme, autonomies (3,25\%). Educació i universitat (2,84\%). Diversos $(8,81 \%)$.

10. La publicació d'aquesta revista s'inicia per part del CIS l'any 1978, en substitució de la Revista Española de la Opinión Pública. 
Si es parteix de la classificació que s'ha utilitzat en aquest treball, i utilitzant com a referència el primer i l'últim quinquenni del període considerat, es veu que tan sols hi ha dues àrees temàtiques que perden importància relativa: [07] Sociologia política; relacions internacionals, i [19] Sociologia de la cultura i l'art. D'altra banda, incrementen molt la seva presència els articles vinculats a les temàtiques [2] Teoria sociològica, [9] Sociologia del gènere, [11] Identitats col-lectives; moviments socials i acció col-lectiva; participació social, i [15] Sociologia de les migracions, minories ètniques i multiculturalitat.

Pel que fa a la procedència dels articles, cal destacar positivament tant el gran nombre d'institucions que hi participen com l'elevat nombre d'articles procedents d'institucions, universitats i centres de recerca ubicats fora del territori espanyol, la qual cosa, sense cap mena de dubte, s'ha d'interpretar com un signe de qualitat i prestigi que la revista ha anat assolint amb els anys. Una qüestió diferent, però també important, és la col-laboració institucional dels autors a l'hora d'intentar esbrinar xarxes de col-laboració o l'existència de "col-legis invisibles». En aquest sentit, les dades no són concloents, però pot apuntar-se la tendència que certes universitats actuïn com a dinamitzadores de les xarxes de col-laboració institucional. Malauradament, les dades de què es disposa són insuficients per utilitzar tècniques d'escalament multidimensional que permetin representar en un espai el mapa de les institucions que colllaboren entre elles a l'hora de dur a terme les investigacions que es divulguen mitjançant la revista PAPERS, o bé altres tècniques similars que ens permetin aprofundir en aquest aspecte de l'activitat dels sociòlegs, la qual cosa, sens dubte, suposa un repte obert vers el futur. 


\section{Annex 1. Institucions d'origen dels col-laboradors de la revista PAPERS}

Institució

País

Caisse Nationale d'Assurance Vieillesse des Travailleurs Salariés

Centre de Sociologie Européenne. París

Centro de Investigaciones y Desarrollo de la Música Cubana

Centro de Investigaciones y Estudios Superiores en Antropología Social.

CESIS-Centro de Estudios para a Intervenção Social

Consejo Superior de Investigaciones Científicas

DEDALUS

Dirección General de Migraciones

Facultad Latinoamericana de Ciencias Sociales

Fundació CIDOB

Gabinete de Prospección Sociológica. Presidencia del Gobierno Vasco

IESA-CSIC de Andalucía

INEF-Catalunya

Institut Català d'Estudis Mediterranis

Institut d'Estudis Catalans

Instituto de Cooperación con el Mundo Árabe

London School of Economics

Maned School of Applied Social Science. Care Western University. Ohio

National Technical University

National Centre for Social Research

Oficina de la UNESCO per a la Ciència i la Tecnologia al Sud-est Asiàtic. Jakarta

PARSEC. Associazione Ricerca e Interventi Sociali

SOS Racisme

UNED

Universidad Autónoma de Aguascalientes

Universidad Autónoma de Madrid

Universidad Complutense de Madrid

Universidad de La Paz

Universidad de Tampere

Universitat Autònoma de Barcelona

Universitat de Barcelona

Universitat d'Alacant

Universiteit van Amsterdam

University of Boston

Universität Bremen

University of California

Universitat of Canterbury

Università di Catania

Università di Firenze

Universidad de Granada

Universität Hannover

Universidad de La Habana

Universidad de La Laguna

França

França

Cuba

Mèxic

Portugal

Espanya

Itàlia

Espanya

Costa Rica

Espanya

Espanya

Espanya

Espanya

Espanya

Espanya

Espanya

Regne Unit

EUA

Grècia

Grècia

Indonèsia

Itàlia

Espanya

Espanya

Mèxic

Espanya

Espanya

Bolívia

Finlàndia

Espanya

Espanya

Espanya

Holanda

EUA

Alemanya

EUA

Anglaterra

Itàlia

Itàlia

Espanya

Alemanya

Cuba

Espanya

Universidad de La Rioja

Espanya

Universidad de Las Palmas de Gran Canaria

Espanya 


\begin{tabular}{|c|c|}
\hline Institució & País \\
\hline Universidad de Los Andes & Colòmbia \\
\hline Universidad de Málaga & Espanya \\
\hline Universidad de Murcia & Espanya \\
\hline Universidad de Oviedo & Espanya \\
\hline Université du Québec & Canadà \\
\hline Universidad de Salamanca & Espanya \\
\hline Universidade de Santiago de Compostela & Espanya \\
\hline Universidad de Sevilla & Espanya \\
\hline Université de Toulouse & França \\
\hline Universidad de Valladolid & Espanya \\
\hline Universidad de Vigo & Espanya \\
\hline Universidad de Zaragoza & Espanya \\
\hline Universidad del País Vasco & Espanya \\
\hline Universidad Nacional Autónoma de México & Mèxic \\
\hline Universidad Nacional de Córdoba & Argentina \\
\hline Universidad Nacional de Luján & Argentina \\
\hline Universidad Pública de Navarra & Espanya \\
\hline Universidade Aberta & Portugal \\
\hline Universidade da Coruña & Espanya \\
\hline Universidade Nova de Lisboa & Portugal \\
\hline Università di Padova & Itàlia \\
\hline Università degli Studi di Napoli Federico II & Itàlia \\
\hline Universität Bielefeld & Alemanya \\
\hline University of Chicago & EUA \\
\hline Universitat de Girona & Espanya \\
\hline Universität Hamburg & Alemanya \\
\hline Universität Heidelberg & Alemanya \\
\hline Universitat de Lleida & Espanya \\
\hline Universitat de València & Espanya \\
\hline Universität Konstanz & Alemanya \\
\hline Universitat Politècnica de Catalunya & Espanya \\
\hline Universitat Pompeu Fabra & Espanya \\
\hline Universitat Rovira i Virgili & Espanya \\
\hline Université de Genève & Suïssa \\
\hline University of Aarhus & Dinamarca \\
\hline Université Pantheón-Sorbone. París I & França \\
\hline University of Göteborg & Suècia \\
\hline University of London & Regne Unit \\
\hline University of Sussex & Regne Unit \\
\hline University of Wollongong & Austràlia \\
\hline Ritsumeikan Asia Pacific University & Japó \\
\hline Yale University & EUA \\
\hline
\end{tabular}




\section{Bibliografia}

Bellavista, J.; Turpin, T.; Hill, S.; De Miguel, J. (1998). «Cultura organizativa de investigadores y entorno político y social». Papers, 54, p. 79-109.

DURÁN HERAS, M.A. (2001). "La actual institucionalización de la sociología en España». A Del Campo, S. (dir.). Historia de la sociología española. Barcelona: Ariel.

FERNÁNDEZ, O. (1991). «El análisis de cluster: aplicación, interpretación y validación». Papers, 37, p. 65-76.

GARFIELD, E. (1978). «Citation data as science indicators». A ELKANA, Y.; LENDERBERG, J.; Merton, R.K. (eds). Toward a metric of science. Nova York: John Wiley \& Sons.

GORDON, M.D. (1980). «A critical reassessment of inferred relations between multiple authorship, scientific collaboration, the production of papers and their acceptance for publication». Scientometrics, 2, núm. 3, p. 193-201.

HiCKS, D. (1999) «The difficulty of archieving full coverage of international social science literature and the bibliometric consequences». Scientometrics, 44, núm. 2, p. 193-215.

HiRSCH, W.; SingLETON, J.F. (1965). Research support, multiple autorship and publication in sociological journals 1934-1964. Preprint no publicat. Vegeu: LóPEZ LÓPEZ, P.; ESCALADA LÓPEZ, C. (1999).

LAWANI, S.M. (1986). "Some bibliometric correlates of quality in scientific research». Scientometrics, 9, núm. 1, p. 13-25.

LÓpez López, P.; EsCALAdA López, C. (1999). "Veinte años de sociología española a través de la Revista Española de Investigaciones Sociológicas (1978-1997)». Revista General de Información y Documentación, 9, núm. 1, p. 161-173.

Marín, X.; Miguel, F.J.; Noguera, J.A.; Rambla, X.; Taguenca, J. (1993). «El discurs científic i els processos d'institucionalització científica a la sociologia. El cas de la revista Papers (1973-1993)». Papers, 42, p. 49-104.

MedinA, E. (1982). "Teorías y orientaciones de la sociología de la ciencia». REIS, 20, p. 7-58.

- (1983). "La polémica internalismo/externalismo en la historia y la sociología de la ciencia». REIS, 23, p. 53-76.

Navarro López, M. (2001). "La investigación social aplicada en España». A DEL CAMPO, S. (dir.). Historia de la sociología española. Barcelona: Ariel.

PRICE, D.J.S. (1980). «Ciencia y tecnología: distinción e interrelaciones». A BARNES, B.; KuHN, T.S.; MERTON, R.K. i altres. Estudios sobre sociología de la ciencia. Madrid: Alianza.

Sanz Casado, E.; García Zorita, C.; García Romero, A.; Mondrego Rico, A. (1999). "La investigación española en economía a través de las publicaciones nacionales e internacionales en el período 1990-1995». Revista de Economía Aplicada, VII, núm. 20, p. 113-137.

SHILS, E. (1971). Génesis de la sociología contemporánea. Madrid: Seminarios y Ediciones.

SURIÑACH, J. i altres (2002). "La investigación regional en España: un análisis bibliométrico». Investigaciones Regionales, 1, p. 107-137.

TEZANOS, J.F. (1995). La explicación sociológica: una introducción a la sociología. Madrid: UNED. 